This is an Accepted Manuscript (AM) version of the article:

Tasos Spiliotopoulos \& Ian Oakley (2021). Altruistic and selfish communication on social media: The moderating effects of tie strength and interpersonal trust. Behaviour \& Information Technology, 40:3, 320-336, DOI: 10.1080/0144929X.2019.1688392

The Version of Record (VoR) is available at: https://doi.org/10.1080/0144929X.2019.1688392

\title{
Altruistic and selfish communication on social media: The moderating effects of tie strength and interpersonal trust
}

\section{Tasos Spiliotopoulos}

Madeira Interactive Technologies Institute, University of Madeira, Funchal, Portugal

tspiliot@gmail.com

https://orcid.org/0000-0002-9573-8360

\section{Ian Oakley}

School of Design and Human Engineering, UNIST, Busan, South Korea

ian.r.oakley@gmail.com

https://orcid.org/0000-0001-5834-8577

Corresponding author: Tasos Spiliotopoulos 


\section{Altruistic and selfish communication on social media: The moderating effects of tie strength and interpersonal trust}

Individuals share a diversity of content on social media for a variety of reasons. Research has often described and explained disclosure via the application of a subjective cost-benefit analysis framed around reciprocity, suggesting that people communicate selfishly motivated by the expectation of receiving something in return. This paper investigates the moderating effects of tie strength and interpersonal trust on the relationship between expected reciprocity and intensity of communication between two social media connections. A Facebook application presented participants with a random set of their friends and asked them to rate their friendships in terms of these values. Overall, 90 participants rated 1728 friendships, while the application collected 11 activity variables depicting the actual communication that has taken place in each pair of connections. A principal component analysis was used to distinguish between text- and photograph-related communication, and two moderated multiple regressions were conducted to establish the moderating effects. The results show significant moderating effects of tie strength and trust on the communication around photographs, but not around text. This study contributes to communication research by explicating the ways that tie strength and trust affect patterns of communication on social media. Implications for social media researchers and designers are discussed.

Keywords: Online disclosure; Tie strength; Trust; Reciprocity; Rational choice theory; Photographs

Word count: 8985 words (excluding references) 


\section{Introduction}

Social Network Sites (SNSs) are becoming increasingly larger parts of our everyday lives and influence the way we communicate and share information with one another. Facebook, for example, currently reports 2.27 billion monthly active users, with 1.49 billion of them on average logging on the site daily (Facebook, 2019). As SNSs become richer in features and more diffused in the population, there are both more types of content and more content overall that is being shared among the users. The ability to create and share user-generated content (Kaplan \& Haenlein, 2010), to reshare or forward content by others thus creating cascades of information (Bakshy, Rosenn, Marlow, \& Adamic, 2012) and to provide feedback to content shared by others, for example in the form of comments, favourites or likes (Levordashka, Utz, \& Ambros, 2016) have been described as main characteristics and appeals of SNSs. Understanding the specifics of these online interactions can lead to better design of systems and inform social theory.

Digital-mediated communication, and especially the particulars of how and why we share information on SNSs, has attracted a considerable amount of research attention (e.g. Abramova, Wagner, Krasnova, \& Buxmann, 2017; Quinn, 2016). However, an interdisciplinary review of informational privacy research has shown that the majority of empirical studies tend to view the individual as the salient unit of analysis, something that has been at the expense of our understanding at other levels of analysis (Smith, Dinev, \& Xu, 2011). Articulating a list of connections (e.g. friends on Facebook) and interacting with these connections around usergenerated content distinguishes SNSs from other communication technologies (boyd \& Ellison, 
2007), and thus it is important to study SNS disclosure at the dyadic level as well, that is using pairs of users as the unit of analysis.

Borrowing theoretical frameworks from economics, researchers have often attempted to describe and explain disclosure at the dyadic level via the application of a subjective cost-benefit analysis. This cost-benefit analysis postulates that users act as rational, self-interested actors that constantly engage in a decision-making process where they evaluate the perceived personal benefits of a specific disclosure against the probability and severity of potential privacy risks (Dienlin \& Metzger, 2016). Such a decision-making process is often expressed as a function of expected reciprocity, meaning that we engage in communication with a specific person because we want them to communicate back with us in return (Cook, Cheshire, Rice, \& Nakagawa, 2013). In other words, this strand of research characterizes online interactions as predominantly selfish (i.e. motivated by the expectation of reciprocity) and questions the possibility of an otherwise altruistic motivation (i.e. without the expectation of reciprocity) (Kollock, 1999). However, further work has argued that a direct application of this cost-benefit analysis that is centred around expected reciprocity may underestimate the importance of other factors that influence our online behaviour, such as social and organizational context (Nissenbaum, 2009; Pelaprat \& Brown, 2012). Research also shows that the disclosure of information is influenced by specific dyadic characteristics, such as tie strength (Wang, Burke, \& Kraut, 2016) and interpersonal trust (Joinson, Reips, Buchanan, \& Schofield, 2010). For example, when contemplating a potential online interaction with a very close friend or with an acquaintance recently met at a conference, one would consider communicating and eliciting reciprocal communication for different reasons and to different ends in each case. 
The purpose of the current study is to further investigate this assumption of a SNS user as a self-interested rational actor. To this end, we focus our attention on the decision-making process that underpins SNS communication and, in particular, the factors that affect the relationship between expected reciprocity and communication. To achieve this, we first model communication between pairs of Facebook friends as a function of expected reciprocity. For each pair, we further hypothesise that the strength of the tie with the other person and the trust in them will have a moderating effect on this relationship between expected reciprocity and intensity of communication. We examine this moderating effect for two types of content, textrelated and photograph-related. Explicating the relationships among these concepts can give us useful insights into how SNS users reason about disclosure. In turn, this can inform theories of online social behaviour and provide design recommendations that better support SNS users' privacy, convenience and engagement.

\section{Related work}

\subsection{Disclosure on SNSs}

People make use of SNSs to share a diversity of content to multiple audiences. SNS users share personal information to their connections in the platform not only actively, such as via status updates, comments, and photographs, but also passively through information revealed in their profiles, such as dates of birth, relationship information and events they are interested in attending. Furthermore, even information that is forwarded or reshared from third parties, although not personal in content, can have personal implications; for example, sharing a specific news story may imply that the sharer endorses or agrees with the content and that a receiver will find it worthwhile for their attention. Thus, communication is often studied in terms of acts of 
self-disclosure, traditionally defined as 'any message about the self that a person communicates to another' (Wheeless \& Grotz, 1976) with a clear implication that this communication is deliberate (Greene, Derlega, \& Mathews, 2006). Online self-disclosure can reduce the uncertainty of dyadic interactions (Tidwell \& Walther, 2002) and it has been shown that people like those who self-disclose to them (Jiang, Bazarova, \& Hancock, 2011; Kashian, Jang, Shin, Dai, \& Walther, 2017). As their friend networks increase in size over time and comprise different and potentially conflicting social spheres, SNS users can find it challenging to manage their sharing strategies and behaviours (Binder, Howes, \& Sutcliffe, 2009; Marder, Joinson, \& Shankar, 2011; Vitak, 2012). In response to this problem, SNSs allow their users to fine-tune sharing by creating predefined lists or 'circles' of connections, or to select the recipients of their messages on an ad-hoc case-by-case basis (Kairam, Brzozowski, Huffaker, \& Chi, 2012; Kelley, Brewer, Mayer, Cranor, \& Sadeh, 2011).

\subsubsection{Photograph-related sharing}

In addition to text communication, photo sharing has emerged as a very popular activity on SNSs. This trend is partly fuelled by the proliferation of smartphones that allow users to take pictures with the camera of their devices and quickly share them on the mobile versions of SNS applications; in fact, a recent report shows that $95.1 \%$ of active user accounts access Facebook via smartphone (Statista, 2018). Sharing photographs captured by smartphones has been described as a distinct form of self-impression management, in that it allows the dynamic reconfiguration of private/public boundaries by disclosing more information about oneself than verbal communication (Lee, 2009). Research suggests distinct but overlapping roles for sharers of photographs online, distinguishing between creators of photographic content (i.e. users that post photos they have taken themselves) and curators (i.e. users that post photos they have found 
online) (Pew Research Center, 2013). Specifically for Facebook, sharing, tagging and viewing photographs have been grouped into a distinct motivation for using the service (Joinson, 2008; Spiliotopoulos \& Oakley, 2013). Tosun (2012) has argued that active and passive ways of involvement with photos on Facebook are motivated by separate factors, while other research has found that different patterns of photo-related activity are associated with different personality characteristics (Eftekhar, Fullwood, \& Morris, 2014). A qualitative analysis of college students' Facebook photos described photos as a means for strategic representation of a social group and social life with a focus on the connection and effective communication among the students, something that goes beyond merely documenting college life (Mendelson \& Papacharissi, 2010). An online survey identified six gratifications for digital photo sharing on Facebook, namely affection, attention seeking, disclosure, habit, information sharing, and social influence (Malik, Dhir, \& Nieminen, 2016). Finally, a recent study found that photograph sharing on Facebook varies with relationship type (Houghton, Joinson, Caldwell, Marder, \& Collins, 2018), thus highlighting the importance of the relationship between the discloser and the recipient in photorelated sharing.

\subsection{Communication as a function of expected reciprocity}

While much evidence suggests that privacy is a universal human need and needs to be upheld, self-disclosure confers numerous objective and subjective benefits (Acquisti, Brandimarte, \& Loewenstein, 2015). In fact, current privacy and communication scholarship is often traced back to the Rational Choice Theory (RCT) (Scott, 2000) and its application to social interactions, the Social Exchange Theory (Cook et al., 2013; Homans, 1958), which posit that human relationships are formed by applications of a subjective cost-benefit analysis. This suggests that individuals engage in a decision-making process whereby they weigh the perceived benefits of 
their disclosure activity against the potential privacy risks (Joinson \& Paine, 2007; Laufer \& Wolfe, 1977), a process that has led to the development of a Privacy Calculus model (Dienlin \& Metzger, 2016; Dinev \& Hart, 2006; Krasnova, Spiekermann, Koroleva, \& Hildebrand, 2010). However, the complexity of social relations makes it difficult to assess the costs and benefits of specific online interactions, raising important questions about this rational-actor approach (Pelaprat \& Brown, 2012). Thus, although research has found both SNS use, in general, and disclosure on SNSs, in particular, to be associated with numerous objective and subjective benefits, not all of these benefits can be explained as results of goal-directed actors making selfinterested decisions. Instead, many of these benefits may be considered products or externalities resulting from more complex social processes. Indicatively, studies show that certain motivations and patterns of Facebook use and self-disclosure are associated with increased social capital (Ellison, Steinfield, \& Lampe, 2007), formation, maintenance and development of relationships (Krasnova et al., 2010; Tosun, 2012), social support (Huang, 2016), relational intimacy (Park, Jin, \& Annie Jin, 2011), self-esteem (Steinfield, Ellison, \& Lampe, 2008), subjective well-being (Burke, Marlow, \& Lento, 2010; Huang, 2016; Islam \& Patil, 2015; Kim \& Lee, 2011), positive emotional states (Neubaum \& Krämer, 2015), college adjustment (Yang \& Brown, 2015) and political expression (Yu, 2016). What's more, these perceived benefits may be at odds with one another; for example, someone may post their political opinions online in order to attain the personal gratification of political expression, but this action may in turn alienate part of their audience. This observation highlights the complexity of the relationship between perceived benefits and intentionality of interaction, and suggests an examination of interaction at the dyadic relationship level. 
One way of describing this cost-benefit analysis at the dyadic level is through the assumption that expected reciprocity is a driver for communication; in other words, we disclose information because we want others to disclose in turn (Contena, Loscalzo, \& Taddei, 2015; Cook et al., 2013; Greene et al., 2006; Kollock, 1999; Taddicken, 2014). For example, Barak and Gluck-Ofri (2007) found positive correlations between the measures of self-disclosure in messages and responses to them in discussion forums and Joinson (2001) found that participants in a study divulged a higher quantity of information about themselves when they had received some self-disclosing information about the experimenter beforehand (albeit their answers were not more revealing or intimate). A recent study on gift exchanges on Facebook found that receiving a digital gift causes individuals to be more likely to give a gift in the future, and that this reciprocal activity is strongly influenced by social factors (Kizilcec, Bakshy, Eckles, \& Burke, 2018). In fact, reciprocity has been established as a distinct gratification users attain from using SNSs and as an antecedent of SNS adoption (Pai \& Arnott, 2013). Norms of reciprocity were also found to directly influence affective trust and perceived community support (SánchezFranco \& Roldán, 2015). Further research has revealed a positive relation between receiving a great number of likes and comments from Facebook friends and the level of life satisfaction (Mayol \& Pénard, 2017). On the other hand, receiving few responses from one's Facebook friends was found to threaten the needs for belonging, self-esteem, control, and meaningful existence (Greitemeyer, Mügge, \& Bollermann, 2014).

Hence, proponents of the rational choice approach for explaining interpersonal communication have put expected reciprocity at the heart of people's decision-making process. This approach argues that all social phenomena can be explained as the aggregation of discrete, isolated decisions made by individuals, and that these individuals behave as rational actors 
pursuing their own self-interest (Scott, 2000; Sen, 1997). At the level of these isolated decisions of interaction, behaviour is considered to be dominated by the expectation of reciprocity (Kollock, 1999). Thus, this assumption effectively argues that online interactions are predominantly selfish (i.e. motivated by the expectation of reciprocity from the recipient) and doubts the possibility of otherwise altruistic motivations (i.e. without the expectation of reciprocity). Further work, however, has argued that a rigid, direct application of this cost-benefit analysis centred directly around expected reciprocity underplays the importance of many factors that influence our online behaviour, and that privacy and disclosure online are, in fact, contextually determined (Nissenbaum, 2009; Pelaprat \& Brown, 2012; Quinn \& Papacharissi, 2018). Pelaprat and Brown (2012), for example, refer to concepts such as culture, history, relationships and moral commitments that may subvert this assumption of a self-interested rational communicator.

Overall, the main postulation of RCT as applied to online social behaviour suggests an understanding of online disclosure via the application of a subjective cost-benefit analysis framed around reciprocity. In other words, people are theorized to act as goal-directed, selfish actors that share content with their Facebook connections with the expectation of receiving communication in return. While research suggests that such a rational choice approach can provide useful insights into online behaviour, there are indications that this relationship between expected reciprocity and online disclosure is more complex and should be studied more closely. This paper investigates the roles of tie strength and interpersonal trust as potential moderators of this relationship and puts forward pertinent hypotheses in the following sections.

\subsection{Tie strength}

Tie strength was introduced by Granovetter (1973) as a combination of the amount of time, 
emotional intensity, intimacy (measured as mutual confiding), and reciprocal services devoted to a relationship, with all these factors being independent but correlated. More simply, tie strength can refer to the bonding level or closeness between two people, and a tie is typically characterized as strong or weak. Strong ties are the people that are structurally (Ellison et al., 2007; Friedkin, 1980) and emotionally (Marsden \& Campbell, 1984; Wellman \& Wortley, 1990) close to someone, such as family and close friends, while weak ties are looser or shallower relationships (i.e. acquaintances). With regards to computer-mediated communication, research has argued that strong ties can influence each other to adapt and expand their use of media to support the exchanges important to their tie, but weak ties are dependent on common means of communication and protocols established by others (Haythornthwaite, 2002). More recent research has examined how the dimensions of tie strength map onto social media usage (Gilbert \& Karahalios, 2009; Jones et al., 2013; Luarn \& Chiu, 2015).

Early seminal research has shown clear and distinct benefits from communicating both with strong and weak ties. Granovetter (1973) demonstrated the value of weak ties; because they are in contact with different social circles, they can be bearers of novel information and can be useful in tasks such as looking for a job. Wellman and Wortley (1990) illustrated the value of strong ties for the provision of different kinds of social support, such as emotional aid, small services, and companionship. Interestingly, more recent studies have provided evidence of a more nuanced and tangled view of the effects of tie strength on SNSs. While sociological studies have indicated that weak ties can provide better and more novel information (e.g. Granovetter, 1973), answers to questions that were asked through the status message feature of Facebook from strong ties provided a subtle increase in useful and novel information over answers from weak ties (Panovich, Miller, \& Karger, 2012). Communication with strong ties was also found to 
be more predictive of finding employment within three months than communication with weak ties (Burke \& Kraut, 2013). The same study found that communication with strong ties over social media has been generally associated with improvements in stress levels, social support, and bridging social capital. Tie strength was positively associated with the feeling of happiness and benign envy when browsing Facebook, as opposed to malicious envy which was found to be independent of tie strength (Lin \& Utz, 2015). Weak ties, on the other hand, play an important role for information diffusion in SNSs due to the bridge structural effect in the network (Zhao, Wu, \& Feng, 2011). The literature, for the most part, suggests a positive connection between tie strength and the motivation and action of communicating and sharing information online (Haythornthwaite, 2002; Wang et al., 2016), a relationship that also holds for the sharing of photographs specifically (Gilbert \& Karahalios, 2009; Mendelson \& Papacharissi, 2010).

At the same time, Facebook users will be ostensibly more interested in receiving communication from their closest friends, indicating a link between tie strength and expected reciprocity. In fact, Granovetter's definition of tie strength makes a reference to the 'reciprocal services which characterize a tie' as a factor in building, maintaining, and measuring tie strength (Granovetter, 1973). Reciprocity has been linked to SNS members' common ground (Pai \& Arnott, 2013), which is a significant factor of tie strength, while the mutual exchange of wall posts has been used for the computational calculation of tie strength in data mining studies (Alhazmi \& Gokhale, 2016). Furthermore, if we consider question asking as a form of selfdisclosure, since the fact that one is interested in something is information about them, then eliciting answers to questions on SNSs also constitutes disclosure with an expectation of reciprocity. In this case, tie strength has been also found to affect reciprocity; a survey study of status message Q\&A behaviour on SNSs found that closeness of a friendship was a motivator to 
answer questions (Morris, Teevan, \& Panovich, 2010b) and a small study comparing information seeking between search engines and question asking on Facebook found that many participants' questions were answered by friends they rated as close (Morris, Teevan, \& Panovich, 2010a). It is worth noting, however, that while a positive link between tie strength and expected reciprocity seems intuitive, researchers very early showed that the connection is more nuanced; Altman (1973) noted that the norm of disclosure reciprocity may be stronger early in a relationship than in later stages, and Derlega and colleagues (1976) reported that strangers display more disclosure reciprocity than friends in a social encounter.

Research shows that tie strength is an important factor that affects online disclosure, in general, and that it is a possible moderator of the relationship between expected reciprocity and online disclosure that is suggested by a rational choice approach. We aim to empirically investigate the moderation effects of tie strength on this relationship. That is, we expect that for differing levels of tie strength the relationship between expected reciprocity and actual sharing will also differ. Furthermore, based on the literature that suggests that photographs are a distinct type of content on Facebook, we also differentiate between two different kinds of communication, text-related and photograph-related. Thus, we propose the following hypotheses:

H1: Tie strength moderates the relationship between expected reciprocity and intensity of text-related communication.

H2: Tie strength moderates the relationship between expected reciprocity and intensity of photo-related communication.

\subsection{Interpersonal trust}

Trust has been characterized as an integral part of human interactions, as it allows people to engage in exchanges that leave both parties better off, as well as reduces the cost of these 
transactions (Resnick, 2002; Riegelsberger, Sasse, \& Mccarthy, 2005). Golbeck and Hendler (2006) have provided a definition of interpersonal trust that is particularly suitable for characterizing relationships on SNSs, explaining that 'trust in a person is a commitment to an action based on a belief that the future actions of that person will lead to a good outcome'. Reputation has been described as a useful and important tool for determining the trustworthiness of another person for online interactions (Cheshire \& Cook, 2004). However, interpersonal trust is inherently a personal opinion that can be influenced by several factors, such as past experiences with the other person and their friends, our opinions of actions the person has taken, rumours, and influence by others' opinions (Golbeck, 2005).

A number of studies have consistently shown that trust is a necessary condition for disclosing information and has a positive effect on disclosure either in the case of a website or organization (Mesch, 2012; Wang, Min, \& Han, 2016; Zimmer, Arsal, Al-Marzouq, \& Grover, 2010), or in the case of dyadic relationships offline (Wheeless \& Grotz, 1977) and on SNSs (Millham \& Atkin, 2016; Sheldon, 2009). Researchers, however, have pointed out that the relationship between trust and self-disclosure may be more complex, suggesting that trust has a mediating or moderating effect on the relationship between privacy and self-disclosure (Joinson et al., 2010; Taddei \& Contena, 2013). This means that trust can reduce perceived privacy risks, thereby encouraging SNS users to engage in more disclosure behaviours and in the sharing of more personal information with people they trust (Chen, Pan, \& Guo, 2016; Dwyer, Hiltz, \& Passerini, 2007; Zimmer et al., 2010). Thus, a high degree of trust in the recipient of the disclosure should be even more important in risky situations, such as sharing content that can be more sensitive in nature, like photographs (Gilbert \& Karahalios, 2009; Malik, Hiekkanen, Dhir, \& Nieminen, 2016). Research has also studied the link between interpersonal trust and expected 
reciprocity, as Resnick (2002) explains that '[a]n expectation of continued interaction in the future is helpful in maintaining trust'. Pai and Arnott (2013) expand on this link and argue that without some level of trust in the reciprocity of others, SNS users are reluctant to use the platform for communications that are, to a large extent, highly personal and revealing.

In sum, interpersonal trust is an important factor that affects online disclosure in a positive way. Research also suggests that it may act as a moderator of the relationship between expected reciprocity and online disclosure. This study empirically tests this moderation effect. Thus, we hypothesize that the relationship between expected reciprocity and actual sharing will differ based on interpersonal trust. We also consider two kinds of communication, text-related and photograph-related. So, we have:

H3: Interpersonal trust moderates the relationship between expected reciprocity and intensity of text-related communication.

H4: Interpersonal trust moderates the relationship between expected reciprocity and intensity of photo-related communication.

\section{Method}

\subsection{Tool and procedure}

Participants were invited to complete an online survey in the form of a Facebook application. The first page of the application included a comprehensive description of the study, clearly framed the experiment as an academic study, explained the data collection process, provided the contact details of the researchers, and requested users' consent. In addition to our description, Facebook displays all data-access permissions granted to an application during installation, thus ensuring that the participants had a comprehensive account of the data captured by the study. 
Apart from the basic profile information, the application requested a single extended permission, 'Access posts in your News Feed'. Users can deny extended permissions when they install an application, but the study participants were instructed to accept this permission and, in fact, the application was designed so that it would not proceed unless they did so. The participants had the choice to opt out of the study at any time.

After completing demographic questions, each participant was presented with the name and profile picture of a randomly selected Facebook friend and was asked to answer three questions about them, essentially rating their relationship on three dimensions (tie strength, interpersonal trust, expected reciprocity) by moving a horizontal slider for each question, similar to the approach followed by previous studies for measuring tie strength (Gilbert \& Karahalios, 2009; Luarn \& Chiu, 2015). The slider for each question had to be moved in order for the application to proceed to the next person as a means to ensure that the participant had rated the friendship before moving on to the next. The position of the slider was internally translated into a value between 0 and 1 with a granularity of 0.01 . In the meantime, the application gathered a range of data about the interactions between the two people via the Facebook Application Programming Interface (API) ${ }^{1}$. After rating twenty friends, the participant was presented with summary results (their top friends based on a tie strength algorithm from previous literature) and some light-hearted commentary (e.g. 'The friendship is strong with this one!') about their rated

\footnotetext{
${ }^{1}$ It is worth mentioning that Facebook has been increasingly limiting access to social graph data (i.e. the
} specific connections among persons and between people and digital entities on the platform) via the Facebook API. Most notably, since 2015 a standard third party can only access a user's friends if those friends also use the app. The current study utilizes a dataset from July-August 2012, before this change took effect (see Hogan 2018 for further discussion on the details and the implications of these changes). 
friends in order to incentivise further participation. Participants were then given the option to rate more friends but were also able to quit the application. The application and survey were pilottested with two groups of ten participants each for technical or data collection issues and comprehension/ambiguity of the questions, respectively. These twenty participants rated twenty of their friends each (i.e. 400 friendships) and are not included in the main survey.

\subsection{Participants}

A convenience sample of participants was recruited with a request to complete the online survey through posts in social media, the researchers' institutional student forum, and an online study repository. The survey was implemented and deployed in both the English and Portuguese languages and was targeted to speakers of either language. These are the working languages of the researchers and the institution from which a substantial number of the participants were recruited. Participants with fewer than 20 Facebook friends were excluded because each participant would be later asked to rate 20 friendships and they did not meet this threshold. Participants with more than 1000 Facebook friends were also excluded because they were more likely to be professional accounts. This resulted in a sample of 90 participants (59\% male) who rated 1728 Facebook friendships in total. The participants had a mean age of 26.9 years (SD = 8.7), and came from 11 countries with the vast majority $(n=77,85.6 \%)$ from Portugal and $4.4 \%$ $(\mathrm{n}=4)$ from the USA. They had a mean of 355 Facebook friends $(\mathrm{SD}=218.9$, range $=28-872)$ and reported using Facebook for an average of $13.4(\mathrm{SD}=15.1)$ hours per week. 


\subsection{Measures}

\subsubsection{Survey data}

The study design encouraged each participant to rate at least 20 friendships, so it was important to keep each set of questions short in order to prevent fatigue on the part of the participants. Thus, the three constructs of interest were operationalized using single-item measures. Although single-item measures are not ideal, researchers have provided evidence that under certain conditions single items can function similarly to multiple items in terms of reliability and predictive validity (Alexandrov, 2010; Bergkvist \& Rossiter, 2007; Wanous \& Hudy, 2001). Tie strength was measured with the question 'How strong is your relationship with this person?' with the rating on the slider spanning from 'barely know them' to 'we are very close' and no intermediate markings. Although Gilbert and Karahalios (2009) considered five questions and created five respective models of tie strength, they deemed this question the most general and representative one and decided to focus on this one question for further analysis. Similarly, Panovich and colleagues (2012) employed this single question to validate their tie strength model. Interpersonal trust was measured with the question 'How much do you trust this person?' with the rating on the slider spanning from 'I do not trust this person' to 'I would trust this person with my life'. This specific single-item measure has also been employed to rate interpersonal trust or trustworthiness in many studies across disciplines, from neuroeconomics (Phan, Sripada, Angstadt, \& McCabe, 2010) and organizational science (Evans, Hendron, \& Oldroyd, 2015) to studies of social networks (Schensul \& Burkholder, 2005). In order to measure the expected reciprocity, an ad-hoc item was formulated, 'How much are you looking forward to receiving updates from this person?', with the rating on the slider spanning from 'not at all' to 'very much'. It is worth noting that in the current study the concept of expected reciprocity is 
operationalized contextually, that is it refers to actions and attributes within Facebook. Research has shown that single-item measures are appropriate when a construct refers to a concrete, singular object or attribute (Bergkvist \& Rossiter, 2007), as in this case.

\subsubsection{Behavioural data}

While participants were answering the survey questions for each friend, the application gathered a range of data about the content already shared between the two people. In order to measure text communication between the participant and each of their friends rated we collected six metrics (e.g. the number of timeline posts exchanged), while to measure communication related to photographs we collected five metrics (e.g. the number of likes on a participant's photographs from a friend). No specific timeframe was imposed for the data collection, but it was limited to participants' latest 200 photographs. The variable number of intimacy words exchanged in wall (timeline) posts is based on a sentiment analysis dictionary from previous research (Nielsen, 2011), translated from English to Portuguese and used in both languages. A full list of the metrics and their descriptive values are shown in the results section (Table 2).

\section{Data analysis and results}

Although participants were encouraged to rate at least 20 friendships, they were allowed to rate as many as they wanted. Participants that rated fewer than five friendships (13 participants, 33 cases in total) were removed from the dataset. Further analysis of the responses showed 334 cases where a participant rated a friendship with zero on the tie strength question. This number is in line with a recent study in which participants could only accurately name $72.7 \%$ of their Facebook friends (Croom, Gross, Rosen, \& Rosen, 2016). Because the current study focuses on the disclosures with Facebook connections that the participants actually know, these cases 
(19.7\% of total) were also removed, resulting in a usable dataset of 1361 cases for further analysis, where 77 participants performed a mean of $17.7(\mathrm{SD}=9.9)$ usable ratings each.

\subsection{Tie strength, expected reciprocity, and interpersonal trust}

Table 1 shows descriptive statistics of the answers to the three survey questions and Figure 1 the distributions of the answers.

Table 1. Measures and answers to the survey questions

\begin{tabular}{llccc}
\hline Measure & Survey question & Mean & Median & SD \\
\hline Tie strength & $\begin{array}{l}\text { Q1. How strong is your relationship with this } \\
\text { person? }\end{array}$ & .362 & .30 & .278 \\
$\begin{array}{l}\text { Expected } \\
\text { reciprocity }\end{array}$ & $\begin{array}{l}\text { Q2. How much are you looking forward to } \\
\text { receiving updates from this person? }\end{array}$ & .355 & .32 & .282 \\
Trust & Q3. How much do you trust this person? & .384 & .37 & .284 \\
\hline
\end{tabular}
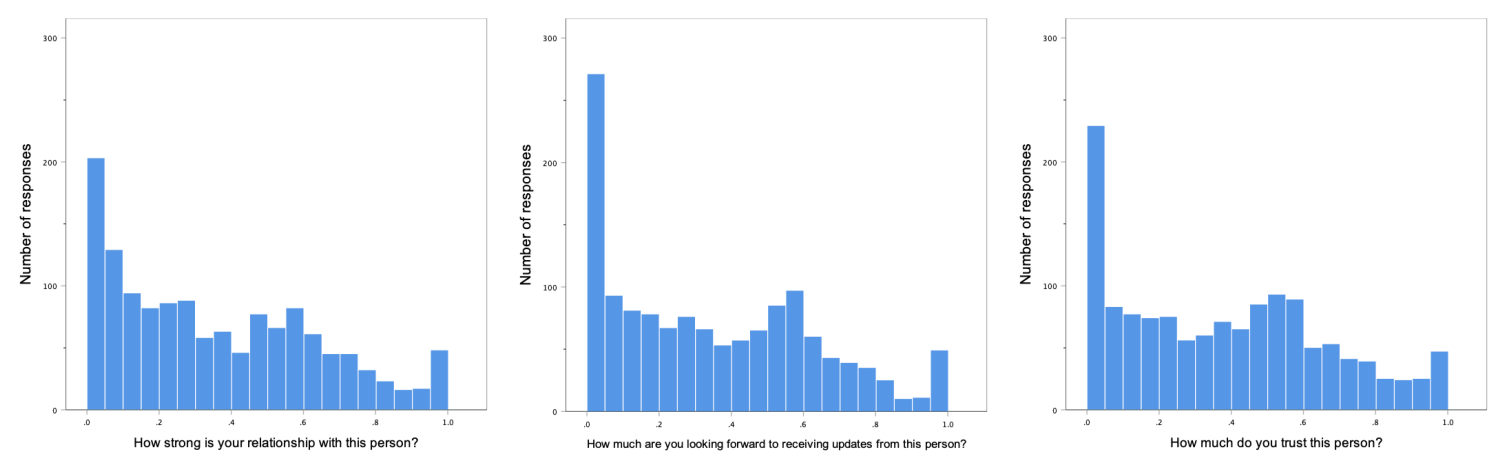

Figure 1. Distributions of the answers to the survey questions from all study participants $(\mathrm{N}=$ 1361) 


\subsection{Measuring intensity of communication}

Previous research has made a strong point that disclosure behaviours are potentially multidimensional, not only in degree but also in kind, and strongly suggests testing behavioural disclosure data for multidimensionality (Knijnenburg, Kobsa, \& Jin, 2013). Principal component analysis and other types of exploratory factor analysis are used for classifying intercorrelated variables under more general (latent) variables, something that is useful for reducing the dimensionality of data. For example, previous studies have used factor analysis to identify discrete dimensions of Facebook usage (Spiliotopoulos \& Oakley, 2015) and network dimensions in social network graphs (Madahali, Najjar, \& Hall, 2019). In the current study, in order to get an accurate composite measure of the text and photograph communication characterizing the friendships, a principal component analysis with orthogonal rotation (varimax) was conducted on the eleven API-collected metrics and the factor scores were used for further analysis. The correlation matrix revealed one case of extreme multicollinearity, namely the relationship between the number of wall (timeline) posts exchanged and the number of participant-initiated posts $(\mathrm{r}=.968, \mathrm{p}<.001)$ leading to the elimination of the latter variable from further analysis. All of the behavioural variables follow power law distributions, and thus we used the logarithm (base ln, after adding a start-value of 1) of these variables to control for skew and then standardized by centring at the mean and dividing by the standard deviation. The Kaiser-Meyer-Olkin measure verified the sampling adequacy for the principal component analysis, $\mathrm{KMO}=.712$. This value confirms the sample size as 'good' (Field 2009; Kaiser 1974) for this analysis. Bartlett's test of sphericity $\chi^{2}(45)=5299, \mathrm{p}<.001$, indicated that correlations between the items are sufficiently large and suitable for this analysis (Field 2009). Harman's single-factor test revealed that the variance explained by a single factor was less than $50 \%$ 
$(34.12 \%)$, suggesting the data are free from common method bias (Podsakoff, MacKenzie, Lee, \& Podsakoff, 2003). Employing an upper threshold of .5 and a lower threshold of .3 for factor loadings, the analysis yielded a two-factor solution. The two factors explain in combination $53.5 \%$ of the variance. Both factors exhibit good reliability with Cronbach's alpha values above .70. The first factor corresponds to text-related communication (i.e. interactions focused around text) and the second factor corresponds to photo-related communication (i.e. interactions focused around photographs). Table 2 shows descriptive statistics of the behavioural data collected by the application and the factor loadings after rotation.

Table 2. Descriptive statistics of items and summary of factors

\begin{tabular}{|c|c|c|c|}
\hline Items & Mean & SD & Factor Loadings \\
\hline \multicolumn{4}{|l|}{ Text-related communication $(\alpha=.773)$} \\
\hline Number of wall (timeline) words exchanged & 3.71 & 12.74 & .89 \\
\hline Wall (timeline) posts exchanged & 0.28 & 0.79 & .79 \\
\hline Comments exchanged on wall (timeline) posts & 0.10 & 0.58 & 69 \\
\hline Intimacy words exchanged on wall (timeline) posts & 0.07 & 0.41 & .65 \\
\hline Likes on participant's wall (timeline) posts & 0.43 & 4.18 & .52 \\
\hline \multicolumn{4}{|l|}{ Photo-related communication $(\alpha=.762)$} \\
\hline Comments on photos where participant is tagged & 0.32 & 1.59 & .77 \\
\hline Likes on photos where participant is tagged & 0.26 & 1.44 & .75 \\
\hline Number of participant's photos where friend is tagged & 0.38 & 1.69 & .72 \\
\hline Likes on participant's photos & 0.04 & 0.37 & .66 \\
\hline Comments on participant's photos & 0.06 & 0.74 & .61 \\
\hline
\end{tabular}


Each participant-friend pair was assigned a score for each of the two factors found in the factor analysis (i.e. one score for text-related communication and one score for photo-related communication). This factor score was calculated based on the 'regression method' for calculating factor scores (Field, 2009, p. 634) and is based on the general idea of a weighted average, so that the items with the higher loading on each factor have a stronger effect on the final score. This method produces scores that have a mean of 0 and a specific variance. We define these factor scores as measures of the intensity of communication taking place for each pair of friends, so that the higher the factor score, more communication has taken place.

\subsection{Testing moderation effects}

In order to investigate moderation effects of the tie strength and trust variables on the relationships between expected reciprocity and the two types of communication (text and photorelated), two moderated multiple regression analyses were conducted. Moderated multiple regression includes the interaction of predictors as a term in the regression equation in order to examine whether or not the interaction of the predictors accounts for incremental variance in the dependent variable beyond the variance accounted for by main effects (Baron \& Kenny, 1986; Hayes, 2018). Before running the regressions, predictor variables were centred and the two interaction variables (expected reciprocity * tie strength, expected reciprocity * trust) were created. Thus, two hierarchical multiple regression models were tested predicting the actual text and photo-related interactions (i.e. the factor scores for each friendship) from the measure of expected reciprocity in the first step, with the interaction variables added in the second step of each model. Examination of collinearity diagnostics for the predictors showed VIF values well below 10 and the tolerance statistics above 0.2 , indicating no multicollinearity in the data (Field, 2009). The Durbin-Watson statistic values were 1.772 and 1.978 confirming that the assumption 
of independence of errors for the two regressions has been met (Durbin \& Watson, 1971; Field, 2009). Overall, both models including only the main effects were significant and the addition of the interaction terms in the second step of each regression resulted also in significant models and accounted for significantly more variance in both cases. Examination of the beta coefficients and their significance showed that two of the four hypotheses were supported.

The model predicting text-related communication from expected communication reciprocity was significant $\mathrm{F}(3,1357)=43.4, \mathrm{R}^{2}=.087, \mathrm{p}<.001$. Addition of the interaction terms in the second step also resulted in a significant model, $\mathrm{F}(5,1355)=27.8, \mathrm{R}^{2}=.093, \mathrm{p}<$ .001 , and accounted for significantly more variance, $\mathrm{R}^{2}$ change $=.006, \mathrm{p}=.016$, indicating potentially significant moderation of tie strength and trust on the relationship between expected reciprocity and actual text-related communication (Table 3). A positive main effect of interpersonal trust on the measures of communication was found, however the two interaction effects were not statistically significant and, thus, H1 and H3 are not supported. 
Table 3. Moderated multiple regression analysis predicting text-related communication.

\begin{tabular}{|c|c|c|c|c|c|}
\hline & \multicolumn{2}{|l|}{ Step 1} & \multicolumn{2}{|l|}{ Step 2} & \multirow{2}{*}{ Hypothesis tested } \\
\hline & $\beta$ & $\mathrm{t}$ & $\beta$ & $\mathrm{t}$ & \\
\hline $\begin{array}{l}\text { Expected reciprocity } \\
\text { (REC) }\end{array}$ & .067 & 1.471 & .053 & 1.158 & \\
\hline Tie strength (TS) & .093 & 1.820 & .078 & 1.481 & \\
\hline Trust (TR) & $.156 * *$ & 3.142 & $.157 * *$ & 3.163 & \\
\hline $\mathrm{REC} \times \mathrm{TS}$ & & & -.011 & -0.202 & H1 (not supported) \\
\hline $\mathrm{REC} \times \mathrm{TR}$ & & & .089 & 1.668 & H3 (not supported) \\
\hline $\mathrm{R}^{2}$ & .087 & & .093 & & \\
\hline Adjusted $\mathrm{R}^{2}$ & .085 & & .090 & & \\
\hline F change & $43.367 * * *$ & & $4.144 *$ & & \\
\hline
\end{tabular}

Notes: $* p<.05, * * p<.01,{ }^{* * *} p<.001$. Beta coefficients shown are standardized. $N=1361$.

The model predicting photo-related communication from expected communication reciprocity was significant $\mathrm{F}(3,1357)=17.4, \mathrm{R}^{2}=.037, \mathrm{p}<.001$. Addition of the interaction terms in the second step also resulted in a significant model, $\mathrm{F}(5,1355)=14.5, \mathrm{R}^{2}=.051, \mathrm{p}<$ .001 , and accounted for significantly more variance, $\mathrm{R}^{2}$ change $=.014, \mathrm{p}<.001$, indicating potentially significant moderation of tie strength and trust on the relationship between selfish motivation for communication and actual photo-related communication (Table 4). A positive main effect of tie strength on the measures of communication was found and both interaction effects were statistically significant, indicating support for both $\mathrm{H} 2$ and $\mathrm{H} 4$. 
Table 4. Moderated multiple regression analysis predicting photo-related communication.

\begin{tabular}{|c|c|c|c|c|c|}
\hline & $\begin{array}{l}\text { Step } 1 \\
\beta\end{array}$ & $\mathrm{t}$ & $\begin{array}{l}\text { Step } 2 \\
\beta\end{array}$ & $\mathrm{t}$ & Hypothesis tested \\
\hline $\begin{array}{l}\text { Expected reciprocity } \\
\text { (REC) }\end{array}$ & -.091 & -1.941 & $-.096^{*}$ & -2.049 & \\
\hline Tie strength (TS) & $.232 * * *$ & 4.405 & $.178 * * *$ & 3.307 & \\
\hline Trust (TR) & .030 & 0.597 & .042 & 0.830 & \\
\hline $\mathrm{REC} \times \mathrm{TS}$ & & & $.213 * * *$ & 3.806 & H2 (supported) \\
\hline $\mathrm{REC} \times \mathrm{TR}$ & & & $-.113^{*}$ & -2.077 & H4 (supported) \\
\hline $\mathrm{R}^{2}$ & .037 & & .051 & & \\
\hline Adjusted $\mathrm{R}^{2}$ & .035 & & .047 & & \\
\hline F change & $17.370 * * *$ & & $9.777 * * *$ & & \\
\hline
\end{tabular}

Notes: $* p<.05, * * p<.01, * * * p<.001$. Beta coefficients shown are standardized. $N=1361$.

In order to aid visualization and interpretation of the moderation effects we generated a set of estimates of the dependent variable (i.e. the factor scores for photo-related communication) from combinations of the moderators (i.e. tie strength and trust) and the main effect variable (i.e. expected reciprocity) using the unstandardized coefficients of the variables in the regression models (including the intercept) and plotted the dependent variable as a function of the moderators and the main effects. Per the recommendation of Hayes (2018, p.244), we used the 16th, 50th, and 84th percentile values (equivalent to a standard deviation below the mean, the mean, and a standard deviation above the mean if a variable is assumed to be normally distributed) to denote low, mid, and high values in the variables. Figures 2 and 3 show visual 
representations of the two significant moderation effects. These visual representations show how the relationship between expected reciprocity and intensity of photo-related communication changes for different values of tie strength (Figure 2) and interpersonal trust (Figure 3).

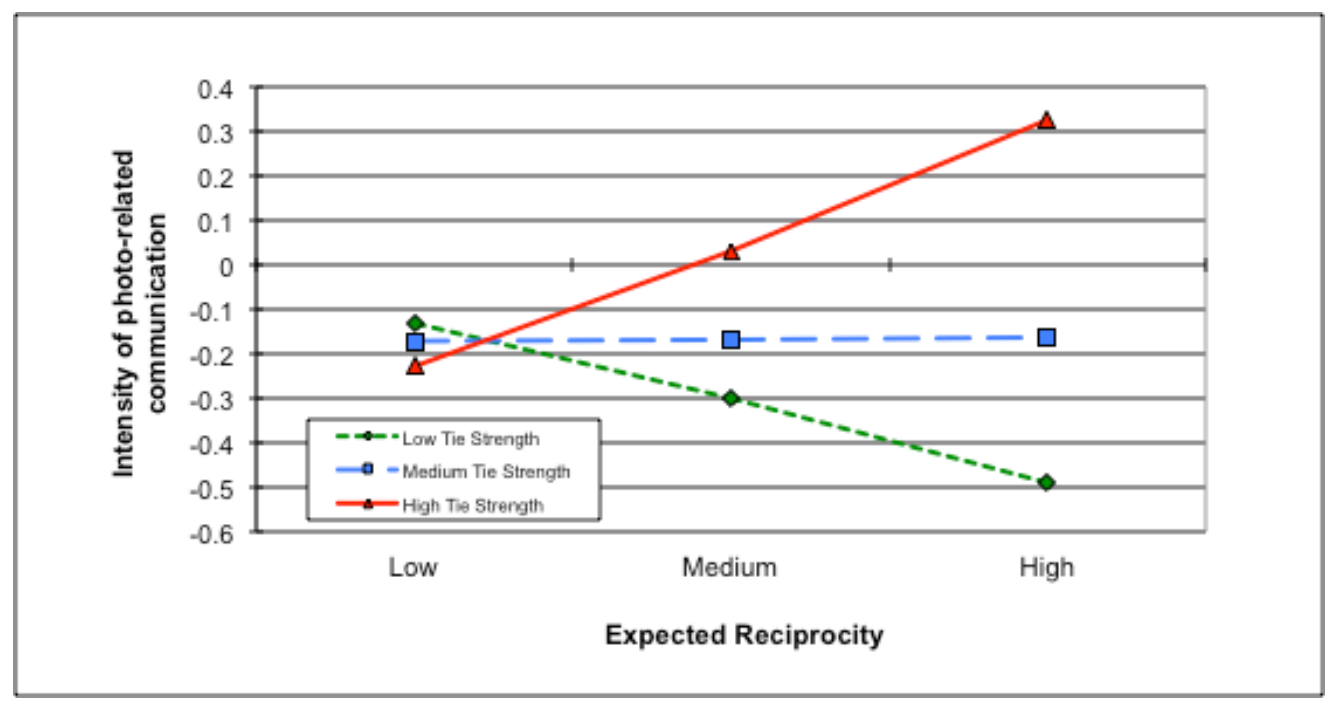

Figure 2. The interaction between levels of tie strength and expected reciprocity on the intensity of photo-related communication (Hypothesis H2)

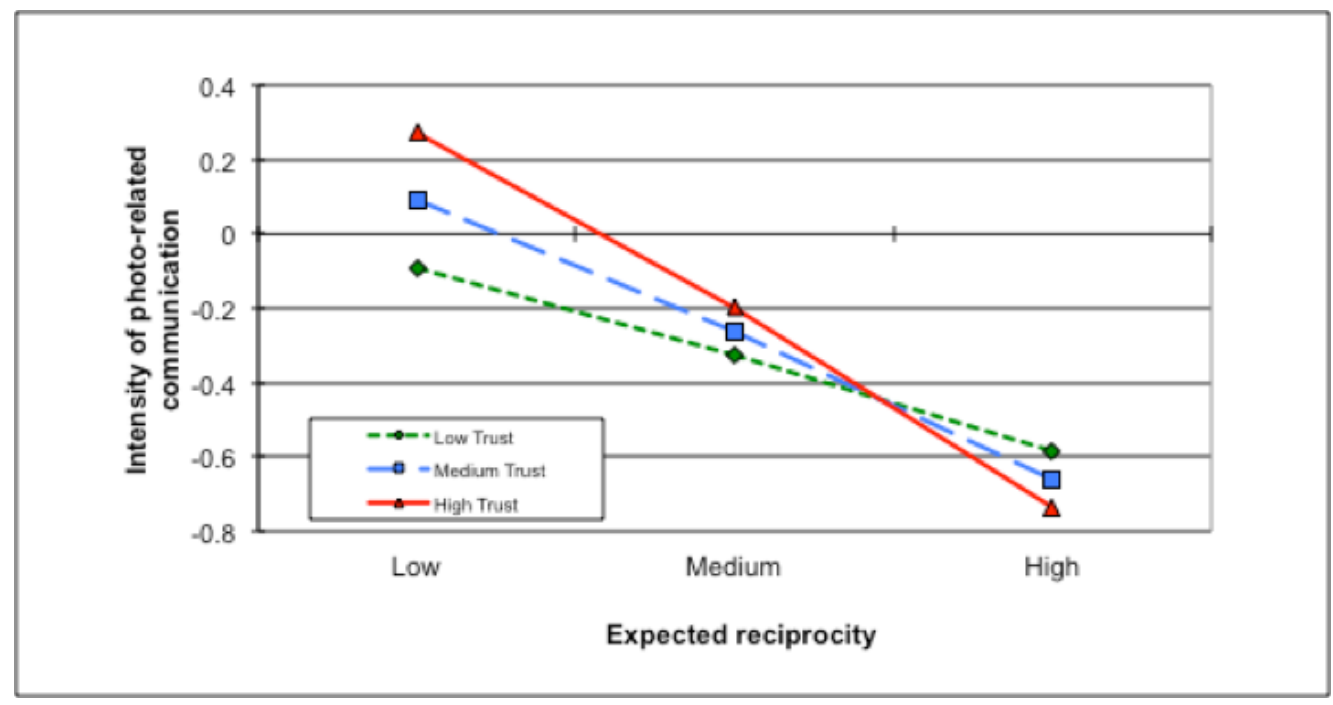

Figure 3. The interaction between levels of trust and expected reciprocity on the intensity of photo-related communication (Hypothesis H4) 


\section{Discussion}

This study examined the moderating effects of tie strength and interpersonal trust on the relationship between expected reciprocity and the actual interactions that take place between specific pairs of Facebook connections. Furthermore, we differentiated between two types of interactions based on content, namely text-related and photo-related. Results show significant moderating effects of tie strength and trust on communication in two out of the four examined cases of moderation, namely the two cases predicting photo-related communication. We also find a positive main effect of interpersonal trust on text-related communication and, similarly, a positive main effect of tie strength on photo-related communication.

With regards to the main effects, prior research has generally suggested a positive association between both tie strength and trust with communication intentions and behaviours (e.g. Millham \& Atkin, 2016; Wang et al., 2016). Our results, however, show that this positive association may differ for different types of content. In particular, we find only the effects of tie strength on photo-related communication and of interpersonal trust on text-related communication to be statistically significant. An explanation for this may be that people that are close to each other in terms of tie strength are more likely to also be physically close and be tagged together in photographs, or communicate with one another with comments and likes around photographs of common places, activities, interests or friends (Gilbert \& Karahalios, 2009). On the other hand, this effect may be less pronounced for connections exhibiting high trust. Trusted people are not necessarily close ties, but may be relied upon for advice, information and answers to questions, which is more likely to take place in the form of text. For example, Levin and Cross (2004) refer to competence-based trust as especially important for knowledge transfer. While our analysis found only two of the four main effects to be statistically 
significant, it may be the case that a larger or more homogeneous sample could detect statistically significant effects for the other relationships as well.

Our results show that tie strength moderates the relationship between expected reciprocity and actual sharing of content around photographs. In particular, for low levels of expected reciprocity the intensity of communication is similar across all levels of tie strength. As the motivation for communication becomes more selfish (i.e. for higher levels of expected reciprocity), the intensity of communication rises for strong ties (such as close friends and family), remains steady for contacts in the medium tie-strength category, and actually decreases for weak ties (such as remote acquaintances) (Fig. 2). In other words, for the strong ties that we are particularly interested in receiving communication from, more actual communication indeed takes place. However, for the weak ties that we are particularly interested in receiving communication from (e.g. an important person that we are not close to, or specific content creator), the intensity of actual communication that takes place decreases. This means that, with regards to photo-related content, the model of a self-interested rational actor may not provide an adequate understanding and interpretation of behaviour, but instead should take into account measures of tie strength.

Interpersonal trust is revealed as a significant moderator that enhances the effect of the predictor on the outcome. Specifically, the more the participant was looking forward to receiving updates from their friend, the less actual photo-related communication was measured between them, and this effect was amplified by the trust the participant showed for their friend (Fig. 3). This moderating effect, however, is weaker than in the tie strength case. The difference in direction between the effects of the two moderators may be due to the structural differences of the two moderators. On one hand, tie strength is considered largely mutual and undirected 
(Granovetter, 1973), for example two close friends or relatives are expected to mutually report their relationship as strong and two distant acquaintances will report their relationship as weak. On the other hand, interpersonal trust can often be one-sided and directed (Golbeck \& Hendler, 2006), for example one may show great trust towards a specific Facebook connection, be that a personal friend, a boss or a public figure, while the other person may not feel the same way and, thus, not be eager to reciprocate the communication. As we collected interaction information that also included two-way communication, this asymmetry in interpersonal trust presents a possible explanation for the moderating effect. Furthermore, the low-reciprocity, low-trust Facebook connections may represent cases where reciprocity is simply not generally expected. Posts about important positive life events, such as having a baby, getting married, or earning a degree are generally shared to larger audiences (Day, 2013) and are more likely to include photos (Bevan et al., 2015). Thus, the large audience for these cases may skew the dataset towards a high intensity of communication around photographs for the low-reciprocity, low-trust cases.

Our findings as a whole, reflect criticisms of RCT that have suggested that the relationship between expected reciprocity and the intensity of communication is not as straightforward as the theory suggests. For example, Pelaprat and Brown (2012) make the theoretical argument that "[online] social actions that solicit a return-action seek to neither profit nor benefit, but rather express a desire to draw in others into social life and relationships". The results in this paper provide empirical support for this argument; we find more actual photograph-related communication taking place between low tie-strength connections when expected reciprocity is low compared to expected reciprocity being high. A similar effect takes place for high trust connections. Weak ties and trusted individuals are persons that we would like to draw further into our social life and relationships, since they can provide novel information 
and connections (in the case of weak ties), and reduce the risk of disclosure (in the case of trusted individuals).

The experimental set-up and data collection approach of the current study have both benefits and limitations. On one hand, this work answers the call of many scholars recommending the study of people's behaviour in realistic situations instead of lab experiments with self-reported behavioural data (e.g. Knijnenburg, Kobsa, and Jin 2013) by employing a Facebook application to collect objective, accurate and granular data about participants' online interactions. This approach is especially important for the study of online disclosure, as previous research has found significant discrepancies between self-reported and actual Facebook use (Junco, 2013), as well as individuals' intentions to disclose personal information and their actual behaviours online (Norberg, Horne, \& Horne, 2007). Furthermore, this experimental format is particularly suitable for empirically studying online disclosure at the dyadic level, something that is a long-standing limitation of disclosure studies that typically focus on the individual as the salient unit of analysis (Smith et al., 2011). On the other hand, it is worth noting that researchers have lately started raising concerns about the quality of API-collected data (e.g. Lomborg \& Bechmann, 2014; Weiler, 2018). In the case of this study, for example, changes to the Facebook API since the data were captured mean that some variables have been replaced or deprecated, and, in fact, API access to friends' data has been limited, making it possible that these kind of studies cannot be easily replicated with high accuracy in the future (Hogan, 2018). Furthermore, in order to keep our questionnaire short, we used single-item measures to describe our constructs of interest. Especially in the case of expected reciprocity, further work may be necessary in order to validate this single question and determine how participants interpret it. Finally, even though we attempted to respect and accommodate users' privacy concerns, it is clear that our sample is 
subject to self-selection bias; not only participants self-selected to be included in the study, but they had to install a custom Facebook application and agree to offer some of their data.

\section{Implications}

\subsection{Theoretical implications}

This work provides insights for communication research by investigating the application of RCT for understanding users' behaviour on SNSs. In particular, this paper puts into question the assumption of a SNS user as a self-interested rational actor and shows that the relationship between expected reciprocity and SNS communication is, in fact, moderated by tie strength and interpersonal trust in specific ways. While previous criticisms of RCT for describing disclosure have emphasized individual differences (Hann, Hui, Lee, \& Png, 2007), environmental cues (John, Acquisti, \& Loewenstein, 2010) and platform interface cues (Gambino, Kim, Sundar, Ge, \& Rosson, 2016), our approach contributes to this body of research by focusing on characteristics of dyadic relationships. Our findings are important for social media researchers studying and modelling SNS behaviour. Future studies of dyadic online interactions should keep in mind the ways that tie strength and interpersonal trust influence the links between motivations for communication and actual behaviour, and include such measures in their models or control for the differences between strong ties and weak ties in their sampling and analyses. The findings in this paper are also important to researchers in economics aiming to understand the limits, applications and possible extensions of RCT (see Sato, 2013 for discussion on these broader topics). Especially, the fledging research area that focuses on the application of behavioural economic theories and practices (such as soft paternalism and nudging) for understanding and motivating SNS behaviour can be of particular benefit (Wang et al., 2014). 
While our study found significant effects of our variables of interest (tie strength and interpersonal trust) on the relationship between expected reciprocity and actual photo-related communication, this was not the case for text-related communication. This calls attention to the ways that photographic content on SNSs can be inherently different to text content and highlights the need for more studies in this area. This distinction between the two types of content is further supported by our finding that Facebook usage can be effectively dimensionalised into photograph-related and text-related. Both the main effects and the moderation effects in our study support the argument that explanations of online interaction should refrain from treating interaction on a specific platform in a monolithic way, but instead could benefit from focusing on specific modes of interaction, such as text and photographs.

\subsection{Practical implications}

Previous theoretical work has argued for the importance of reciprocal interactions for understanding and supporting online activity (Kizilcec et al., 2018; Pelaprat \& Brown, 2012). Our findings show that expected reciprocity does not directly translate to actual communication, but is instead moderated by tie strength and interpersonal trust. This means that simply designing for expected reciprocity is not enough to support online communication, but instead the interactions of tie strength and trust with expected reciprocity should be taken into account. Previous research has identified ways to enhance reciprocity by increasing expected reciprocity on social media, such as designing for 'encounter', providing public visibility of specific actions motivated by reciprocity, and facilitating symbolic exchanges (Pelaprat \& Brown, 2012). The design recommendations arising from the current paper suggest that such design decisions aimed at supporting reciprocity would be more effective when targeted at specific SNS connections based on the characteristics of the relationship with the connection, namely tie strength and 
interpersonal trust. These recommendations can be used as inputs to drive models of behaviour and algorithms that suggest connections to share specific content with or manage visibility of interactions (e.g. in newsfeed-like features). This can enhance the design of SNS platforms and third-party tools that connect to the platforms, as well as SNS users' privacy and convenience. Furthermore, considering that the visibility of actual reciprocal actions is linked to a further desire for reciprocity among observers (Kizilcec et al., 2018), enhancing the effectiveness of actions aimed at reciprocity could lead to increases in the overall engagement of social media users.

\section{Conclusion and future research}

This study contributes to on-going research on privacy and disclosure on social media by explicating the moderating effects of tie strength and interpersonal trust on different types of disclosure. Adding to the work that argues that social media interactions may be influenced by factors outside the remit of a traditional cost-benefit analysis (e.g. Gambino et al. 2016; Pelaprat and Brown 2012) we investigated the roles of these two fundamental concepts in the decisionmaking process of online disclosure and their relationship with expected reciprocity. Taken together, our findings suggest ways that future studies of online interaction could benefit by considering the concepts of tie strength and interpersonal trust as important factors that influence online interactions at the dyadic level.

Facebook allows the sharing of a variety of content, both text-based and photographbased, thus being particularly suitable for studying the differences between the two types of content on the same platform. Future research that takes a broader approach could complement and validate our findings. In particular, the study of sharing practices on a predominantly photobased SNS platform such as Instagram, of different content (e.g. video), the utilization of more 
metrics for characterizing interactions (e.g. more extensive use of sentiment analysis), and the inclusion of different demographic groups, could yield additional insights on the relationship between expected reciprocity and information sharing.

\section{References}

Abramova, O., Wagner, A., Krasnova, H., \& Buxmann, P. (2017). Understanding SelfDisclosure on Social Networking Sites - A Literature Review. In 23rd Americas Conference on Information Systems - AMCIS 2017.

Acquisti, A., Brandimarte, L., \& Loewenstein, G. (2015). Privacy and human behavior in the age of information. Science, 347(6221), 509-514. https://doi.org/10.1126/science.aaa1465

Alexandrov, A. (2010). Characteristics of single-item measures in likert scale format. Electronic Journal of Business Research Methods, 8(1), 1-12.

Alhazmi, H., \& Gokhale, S. S. (2016). Mining Social Capital on Online Social Networks with Strong and Weak Ties. In 2nd International Conference on Open and Big Data (OBD) (pp. 9-16). IEEE. https://doi.org/10.1109/OBD.2016.9

Altman, I. (1973). Reciprocity of Interpersonal Exchange. Journal for the Theory of Social Behaviour, 3(2), 249-261. https://doi.org/10.1111/j.1468-5914.1973.tb00325.x

Bakshy, E., Rosenn, I., Marlow, C., \& Adamic, L. (2012). The role of social networks in information diffusion. In Proceedings of the 21st international conference on World Wide $W e b-W W W$ '12 (p. 519). New York, New York, USA: ACM Press. https://doi.org/10.1145/2187836.2187907

Barak, A., \& Gluck-Ofri, O. (2007). Degree and Reciprocity of Self-Disclosure in Online Forums. CyberPsychology \& Behavior, 10(3), 407-417. https://doi.org/10.1089/cpb.2006.9938

Baron, R. M., \& Kenny, D. A. (1986). The moderator-mediator variable distinction in social psychological research: Conceptual, strategic, and statistical considerations. Journal of Personality and Social Psychology, 51(6), 1173-1182. https://doi.org/10.1037/00223514.51.6.1173 
Bergkvist, L., \& Rossiter, J. R. (2007). The Predictive Validity of Multiple-Item Versus SingleItem Measures of the Same Constructs. Journal of Marketing Research, 44(2), 175-184. https://doi.org/10.1509/jmkr.44.2.175

Bevan, J. L., Cummings, M. B., Kubiniec, A., Mogannam, M., Price, M., \& Todd, R. (2015). How Are Important Life Events Disclosed on Facebook? Relationships with Likelihood of Sharing and Privacy. Cyberpsychology, Behavior, and Social Networking, 18(1), 8-12. https://doi.org/10.1089/cyber.2014.0373

Binder, J., Howes, A., \& Sutcliffe, A. (2009). The problem of conflicting social spheres: effects of network structure on experienced tension in social network sites. In Proceedings of the SIGCHI Conference on Human Factors in Computing Systems (pp. 965-974). https://doi.org/10.1145/1518701.1518849

Boyd, D., \& Ellison, N. (2007). Social Network Sites: Definition, History, and Scholarship. Journal of Computer-Mediated Communication, 13(1), 210-230.

Burke, M., \& Kraut, R. (2013). Using Facebook after Losing a Job : Differential Benefits of Strong and Weak Ties. In Proceedings of CSCW 2013.

Burke, M., Marlow, C., \& Lento, T. (2010). Social network activity and social well-being. In Proceedings of the 28th international conference on Human factors in computing systems CHI '10 (p. 1909). New York, New York, USA: ACM Press. https://doi.org/10.1145/1753326.1753613

Chen, X., Pan, Y., \& Guo, B. (2016). The influence of personality traits and social networks on the self-disclosure behavior of social network site users. Internet Research, 26(3), 566-586. https://doi.org/10.1108/IntR-05-2014-0145

Cheshire, C., \& Cook, K. S. (2004). The Emergence of Trust Networks under Uncertainty Implications for Internet Interactions. Analyse \& Kritik, 26(1), 220-240. https://doi.org/10.1515/auk-2004-0112

Contena, B., Loscalzo, Y., \& Taddei, S. (2015). Surfing on Social Network Sites: A comprehensive instrument to evaluate online self-disclosure and related attitudes. Computers in Human Behavior, 49, 30-37. https://doi.org/10.1016/j.chb.2015.02.042

Cook, K. S., Cheshire, C., Rice, E. R. W., \& Nakagawa, S. (2013). Social Exchange Theory. In 
Handbook of Social Psychology (pp. 61-88). https://doi.org/10.1007/978-94-007-6772-0_3

Croom, C., Gross, B., Rosen, L. D., \& Rosen, B. (2016). What's Her Face(book)? How many of their Facebook "friends" can college students actually identify? Computers in Human Behavior, 56, 135-141. https://doi.org/10.1016/j.chb.2015.11.015

Day, S. (2013). Self-disclosure on Facebook: how much do we really reveal? Journal of Applied Computing and Information Technology, 17(1), 1-6.

Derlega, V. J., Wilson, M., \& Chaikin, A. L. (1976). Friendship and disclosure reciprocity. Journal of Personality and Social Psychology, 34(4), 578-582. https://doi.org/10.1037/0022-3514.34.4.578

Dienlin, T., \& Metzger, M. J. (2016). An Extended Privacy Calculus Model for SNSs: Analyzing Self-Disclosure and Self-Withdrawal in a Representative U.S. Sample. Journal of Computer-Mediated Communication, 21(5), 368-383. https://doi.org/10.1111/jcc4.12163

Dinev, T., \& Hart, P. (2006). An extended privacy calculus model for e-commerce transactions. Information Systems Research, 17(1), 61-80. https://doi.org/10.1287/isre.1060.0080

Durbin, J., \& Watson, G. S. (1971). Testing for serial correlation in least squares regression. III. Biometrika, 58(1), 1-19. https://doi.org/10.2307/2332325

Dwyer, C., Hiltz, S., \& Passerini, K. (2007). Trust and Privacy Concern Within Social Networking Sites: A Comparison of Facebook and MySpace. In AMCIS.

Eftekhar, A., Fullwood, C., \& Morris, N. (2014). Capturing personality from Facebook photos and photo-related activities: How much exposure do you need? Computers in Human Behavior, 37, 162-170. https://doi.org/10.1016/j.chb.2014.04.048

Ellison, N., Steinfield, C., \& Lampe, C. (2007). The Benefits of Facebook "Friends:" Social Capital and College Students' Use of Online Social Network Sites. Journal of ComputerMediated Communication, 12(4), 1143-1168. https://doi.org/10.1111/j.10836101.2007.00367.x

Evans, J. M., Hendron, M. G., \& Oldroyd, J. B. (2015). Withholding the Ace: The Individualand Unit-Level Performance Effects of Self-Reported and Perceived Knowledge Hoarding. Organization Science, 26(2), 494-510. https://doi.org/10.1287/orsc.2014.0945 
Facebook. (2019). Facebook Company Info. Retrieved March 21, 2019, from https://newsroom.fb.com/company-info/

Field, A. (2009). Discovering Statistics Using SPSS (3rd ed.). Sage Publications.

Friedkin, N. (1980). A test of structural features of granovetter's strength of weak ties theory. Social Networks, 2(4), 411-422. https://doi.org/10.1016/0378-8733(80)90006-4

Gambino, A., Kim, J., Sundar, S. S., Ge, J., \& Rosson, M. B. (2016). User Disbelief in Privacy Paradox: Heuristics that Determine Disclosure. In Proceedings of the $2016 \mathrm{CHI}$ Conference Extended Abstracts on Human Factors in Computing Systems - CHI EA '16 (pp. 28372843). ACM Press. https://doi.org/10.1145/2851581.2892413

Gilbert, E., \& Karahalios, K. (2009). Predicting tie strength with social media. In Proceedings of the 27th international conference on Human factors in computing systems - CHI '09 (p. 211). New York, New York, USA: ACM Press. https://doi.org/10.1145/1518701.1518736

Golbeck, J. (2005). Computing and applying trust in web-based social networks. PhD Dissertation. University of Maryland (College Park, Md.).

Golbeck, J., \& Hendler, J. (2006). Inferring binary trust relationships in Web-based social networks. ACM Transactions on Internet Technology, 6(4), 497-529. https://doi.org/10.1145/1183463.1183470

Granovetter, M. S. (1973). The Strength of Weak Ties. The Journal of Applied Psychology, $78(6), 1360-1380$.

Greene, K., Derlega, V. J., \& Mathews, A. (2006). Self-Disclosure in Personal Relationships. In A. L. Vangelisti \& D. Perlman (Eds.), The Cambridge Handbook of Personal Relationships (pp. 409-428). Cambridge: Cambridge University Press. https://doi.org/10.1017/CBO9780511606632.023

Greitemeyer, T., Mügge, D. O., \& Bollermann, I. (2014). Having Responsive Facebook Friends Affects the Satisfaction of Psychological Needs More Than Having Many Facebook Friends. Basic and Applied Social Psychology, 36(3), 252-258. https://doi.org/10.1080/01973533.2014.900619

Hann, I. H., Hui, K. L., Lee, S. Y. T., \& Png, I. P. L. (2007). Analyzing online information 
privacy concerns: An information processing theory approach. Proceedings of the Annual Hawaii International Conference on System Sciences, 24(2), 13-42. https://doi.org/10.1109/HICSS.2007.81

Hayes, A. F. (2018). Introduction to Mediation, Moderation, and Conditional Process Analysis: A Regression-based Approach (2nd ed.). New York: Guilford Press.

Haythornthwaite, C. (2002). Strong, Weak, and Latent Ties and the Impact of New Media. The Information Society, 18(5), 385-401. https://doi.org/10.1080/01972240290108195

Hogan, B. (2018). Social Media Giveth, Social Media Taketh Away: Facebook, Friendships, and APIs. International Journal of Communication, 12(20), 592-611.

Homans, G. (1958). Social Behavior as Exchange. American Journal of Sociology, 63(6), $597-$ 606. https://doi.org/10.1086/222355

Houghton, D., Joinson, A., Caldwell, N., Marder, B., \& Collins, E. (2018). Photographic Disclosure in Facebook and Relational Closeness with Others. In Proceedings of the 51st Hawaii International Conference on System Sciences (Vol. 9, pp. 2078-2087).

Huang, H. Y. (2016). Examining the beneficial effects of individual's self-disclosure on the social network site. Computers in Human Behavior, 57, 122-132. https://doi.org/10.1016/j.chb.2015.12.030

Islam, A. K. M. N., \& Patil, S. (2015). Engagement and Well-being on Social Network Sites. In Proceedings of the 18th ACM Conference on Computer Supported Cooperative Work \& Social Computing - CSCW '15 (pp. 375-382). New York, New York, USA: ACM Press. https://doi.org/10.1145/2675133.2675299

Jiang, L. C., Bazarova, N. N., \& Hancock, J. T. (2011). The Disclosure-Intimacy Link in Computer-Mediated Communication: An Attributional Extension of the Hyperpersonal Model. Human Communication Research, 37(1), 58-77. https://doi.org/10.1111/j.14682958.2010.01393.x

John, L. K., Acquisti, A., \& Loewenstein, G. (2010). Strangers on a Plane: Context-Dependent Willingness to Divulge Sensitive Information. Journal of Consumer Research, 37(5), 858873. https://doi.org/10.1086/656423 
Joinson, A. (2001). Knowing Me, Knowing You: Reciprocal Self-Disclosure in Internet-Based Surveys. CyberPsychology \& Behavior, 4(5), 587-591. https://doi.org/10.1089/109493101753235179

Joinson, A. (2008). Looking at, looking up or keeping up with people? In Proceeding of the twenty-sixth annual CHI conference on Human factors in computing systems - CHI '08 (p. 1027). New York, New York, USA: ACM Press. https://doi.org/10.1145/1357054.1357213

Joinson, A., \& Paine, C. B. (2007). Self-disclosure, Privacy and the Internet. In A. Joinson, K. Y. A. McKenna, T. Postmes, \& U.-D. Reips (Eds.), Oxford Handbook of Internet Psychology (pp. 235-250). Oxford University Press.

Joinson, A., Reips, U.-D., Buchanan, T., \& Schofield, C. B. P. (2010). Privacy, Trust, and SelfDisclosure Online. Human-Computer Interaction, 25(1), 1-24. https://doi.org/10.1080/07370020903586662

Jones, J. J., Settle, J. E., Bond, R. M., Fariss, C. J., Marlow, C., \& Fowler, J. H. (2013). Inferring Tie Strength from Online Directed Behavior. PLoS ONE, 8(1), e52168. https://doi.org/10.1371/journal.pone.0052168

Junco, R. (2013). Comparing actual and self-reported measures of Facebook use. Computers in Human Behavior, 29(3), 626-631. https://doi.org/10.1016/j.chb.2012.11.007

Kairam, S., Brzozowski, M., Huffaker, D., \& Chi, E. (2012). Talking in circles: selective sharing in Google+. In Proceedings of the 2012 ACM annual conference on Human Factors in Computing Systems (pp. 1065-1074). https://doi.org/10.1145/2207676.2208552

Kaplan, A. M., \& Haenlein, M. (2010). Users of the world, unite! The challenges and opportunities of Social Media. Business Horizons, 53(1), 59-68. https://doi.org/10.1016/j.bushor.2009.09.003

Kashian, N., Jang, J., Shin, S. Y., Dai, Y., \& Walther, J. B. (2017). Self-disclosure and liking in computer-mediated communication. Computers in Human Behavior, 71, 275-283. https://doi.org/10.1016/j.chb.2017.01.041

Kelley, P. G., Brewer, R., Mayer, Y., Cranor, L. F., \& Sadeh, N. (2011). An investigation into facebook friend grouping. In IFIP Conference on Human-Computer Interaction (pp. 216233). Springer Berlin Heidelberg. 
Kim, J., \& Lee, J.-E. R. (2011). The Facebook Paths to Happiness: Effects of the Number of Facebook Friends and Self-Presentation on Subjective Well-Being. Cyberpsychology, Behavior, and Social Networking, 14(6), 359-364. https://doi.org/10.1089/cyber.2010.0374

Kizilcec, R. F., Bakshy, E., Eckles, D., \& Burke, M. (2018). Social Influence and Reciprocity in Online Gift Giving. In Proceedings of the 2018 CHI Conference on Human Factors in Computing Systems - CHI '18 (pp. 1-11). New York, New York, USA: ACM Press. https://doi.org/10.1145/3173574.3173700

Knijnenburg, B. P., Kobsa, A., \& Jin, H. (2013). Dimensionality of information disclosure behavior. International Journal of Human Computer Studies, 71(12), 1144-1162. https://doi.org/10.1016/j.ijhcs.2013.06.003

Kollock, P. (1999). The economies of online cooperation: Gifts and public goods in cyberspace. In M. Smith \& P. Kollock (Eds.), Communities in Cyberspace (pp. 220-239). London: Routledge.

Krasnova, H., Spiekermann, S., Koroleva, K., \& Hildebrand, T. (2010). Online social networks: why we disclose. Journal of Information Technology, 25(2), 109-125. https://doi.org/10.1057/jit.2010.6

Laufer, R. S., \& Wolfe, M. (1977). Privacy as a Concept and a Social Issue: A Multidimensional Developmental Theory. Journal of Social Issues, 33(3), 22-42. https://doi.org/10.1111/j.1540-4560.1977.tb01880.x

Lee, D.-H. (2009). Mobile Snapshots and Private/Public Boundaries. Knowledge, Technology \& Policy, 22(3), 161-171. https://doi.org/10.1007/s12130-009-9081-0

Levin, D. Z., \& Cross, R. (2004). The Strength of Weak Ties You Can Trust: The Mediating Role of Trust in Effective Knowledge Transfer. Management Science, 50(11), 1477-1490. https://doi.org/10.1287/mnsc. 1030.0136

Levordashka, A., Utz, S., \& Ambros, R. (2016). What's in a like? Motivations for pressing the like button. Proceedings of the Tenth International AAAI Conference on Web and Social Media (ICWSM 2016), (Icwsm), 623-626.

Lin, R., \& Utz, S. (2015). The emotional responses of browsing Facebook: Happiness, envy, and the role of tie strength. Computers in Human Behavior, 52, 29-38. 
https://doi.org/10.1016/j.chb.2015.04.064

Lomborg, S., \& Bechmann, A. (2014). Using APIs for Data Collection on Social Media. The Information Society, 30(4), 256-265. https://doi.org/10.1080/01972243.2014.915276

Luarn, P., \& Chiu, Y.-P. (2015). Key variables to predict tie strength on social network sites. Internet Research, 25(2), 218-238. https://doi.org/10.1108/IntR-11-2013-0231

Madahali, L., Najjar, L., \& Hall, M. (2019). Exploratory Factor Analysis of Graphical Features for Link Prediction in Social Networks. In S. Cornelius, C. Granell Martorell, J. GómezGardeñes, \& B. Gonçalves (Eds.), Complex Networks X. CompleNet 2019. Springer Proceedings in Complexity (pp. 17-31). Springer, Cham. https://doi.org/10.1007/978-3030-14459-3_2

Malik, A., Dhir, A., \& Nieminen, M. (2016). Uses and Gratifications of digital photo sharing on Facebook. Telematics and Informatics, 33(1), 129-138. https://doi.org/http://dx.doi.org/10.1016/j.tele.2015.06.009

Malik, A., Hiekkanen, K., Dhir, A., \& Nieminen, M. (2016). Impact of privacy, trust and user activity on intentions to share Facebook photos. Journal of Information, Communication and Ethics in Society, 14(4), 364-382. https://doi.org/10.1108/JICES-06-2015-0022

Marder, B., Joinson, A., \& Shankar, A. (2011). Every post you make, every pic you take, I'll be watching you: Behind social spheres on facebook. In Proceedings of the Annual Hawaii International Conference on System Sciences (pp. 859-868).

https://doi.org/10.1109/HICSS.2012.12

Marsden, P. V., \& Campbell, K. E. (1984). Measuring Tie Strength. Social Forces, 63(2), 482501.

Mayol, A., \& Pénard, T. (2017). Facebook use and individual well-being: Like me to make me happier!. In Revue d'économie industrielle (pp. 101-127). De Boeck Supérieur.

Mendelson, A. L., \& Papacharissi, Z. (2010). Look at us: Collective Narcissism in College Student Facebook Photo Galleries. In Z. Papacharissi (Ed.), The Networked Self: Identity, Community and Culture on Social Network Sites (pp. 251-273). Routledge.

Mesch, G. S. (2012). Is online trust and trust in social institutions associated with online 
disclosure of identifiable information online? Computers in Human Behavior, 28(4), 14711477. https://doi.org/10.1016/j.chb.2012.03.010

Millham, M. H., \& Atkin, D. (2016). Managing the virtual boundaries: Online social networks, disclosure, and privacy behaviors. New Media \& Society. https://doi.org/10.1177/1461444816654465

Morris, M. R., Teevan, J., \& Panovich, K. (2010a). A comparison of information seeking using search engines and social networks. In Proceedings of the Fourth International AAAI Conference on Weblogs and Social Media (ICWSM) (pp. 291-294).

Morris, M. R., Teevan, J., \& Panovich, K. (2010b). What Do People Ask their Social Networks, and Why? A Survey Study of Status Message Q\&A Behavior. In Proceedings of the 28th international conference on Human factors in computing systems - CHI '10 (p. 1739). New York, New York, USA: ACM Press. https://doi.org/10.1145/1753326.1753587

Neubaum, G., \& Krämer, N. C. (2015). My Friends Right Next to Me: A Laboratory Investigation on Predictors and Consequences of Experiencing Social Closeness on Social Networking Sites. Cyberpsychology, Behavior, and Social Networking, 18(8), 443-449. https://doi.org/10.1089/cyber.2014.0613

Nielsen, F. (2011). A new ANEW: Evaluation of a word list for sentiment analysis in microblogs. In Proceedings of the ESWC2011 Workshop on "Making Sense of Microposts": Big things come in small packages (pp. 93-98).

Nissenbaum, H. (2009). Privacy in context: Technology, policy, and the integrity of social life. Stanford University Press.

Norberg, P. A., Horne, D. R., \& Horne, D. A. (2007). The Privacy Paradox : Personal Information Disclosure Intentions versus Behaviors. The Journal of Consumer Affairs, 41(1), 100-126. https://doi.org/10.1111/j.1083-6101.2009.01494.x

Pai, P., \& Arnott, D. C. (2013). User adoption of social networking sites: Eliciting uses and gratifications through a means-end approach. Computers in Human Behavior, 29(3), 10391053. https://doi.org/10.1016/j.chb.2012.06.025

Panovich, K., Miller, R., \& Karger, D. (2012). Tie strength in question \& answer on social network sites. Proceedings of the ACM 2012 Conference on Computer Supported 
Cooperative Work - CSCW'12, 1057. https://doi.org/10.1145/2145204.2145361

Park, N., Jin, B., \& Annie Jin, S.-A. (2011). Effects of self-disclosure on relational intimacy in Facebook. Computers in Human Behavior, 27(5), 1974-1983.

https://doi.org/10.1016/j.chb.2011.05.004

Pelaprat, E., \& Brown, B. (2012). Reciprocity: Understanding online social relations. First Monday, 17(10). https://doi.org/10.5210/fm.v17i10.3324

Pew Research Center. (2013). Photo and Video Sharing Grow Online.

Phan, K. L., Sripada, C. S., Angstadt, M., \& McCabe, K. (2010). Reputation for reciprocity engages the brain reward center. Proceedings of the National Academy of Sciences of the United States of America, 107(29), 13099-13104. https://doi.org/10.1073/pnas.1008137107

Podsakoff, P. M., MacKenzie, S. B., Lee, J.-Y., \& Podsakoff, N. P. (2003). Common method biases in behavioral research: A critical review of the literature and recommended remedies. Journal of Applied Psychology, 88(5), 879-903. https://doi.org/10.1037/00219010.88.5.879

Quinn, K. (2016). Why We Share: A Uses and Gratifications Approach to Privacy Regulation in Social Media Use. Journal of Broadcasting \& Electronic Media, 60(1), 61-86. https://doi.org/10.1080/08838151.2015.1127245

Quinn, K., \& Papacharissi, Z. (2018). The contextual accomplishment of privacy. International Journal of Communication, 12(0), 45-67.

Resnick, P. (2002). Beyond Bowling Together: SocioTechnical Capital. In J. M. Carroll (Ed.), HCI in the New Millenium (pp. 247-272). Addison-Wesley.

Riegelsberger, J., Sasse, M. A., \& Mccarthy, J. D. (2005). The mechanics of trust: A framework for research and design. International Journal of Human-Computer Studies, 62(3), 381422. https://doi.org/10.1016/j.ijhcs.2005.01.001

Sánchez-Franco, M. J., \& Roldán, J. L. (2015). The influence of familiarity, trust and norms of reciprocity on an experienced sense of community: an empirical analysis based on social online services. Behaviour \& Information Technology, 34(4), 392-412. https://doi.org/10.1080/0144929X.2014.959455 
Sato, Y. (2013). Rational choice theory. Sociopedia.Isa. https://doi.org/0.1177/205684601372

Schensul, J. J., \& Burkholder, G. J. (2005). Vulnerability, Social Networks, Sites, and Selling as Predictors of Drug use among Urban African American and Puerto Rican Emerging Adults. Journal of Drug Issues, 35(2), 379-408. https://doi.org/10.1177/002204260503500208

Scott, J. (2000). Rational choice theory. In G. Brawning, A. Halcli, \& F. Webster (Eds.), Understanding Contemporary Society: Theories of the Present (pp. 126-138). Sage Publications.

Sen, A. (1997). Maximization and the Act of Choice. Econometrica, 65(4), 745-779.

Sheldon, P. (2009). "I'll poke you. You'll poke me!" Self-disclosure, social attraction, predictability and trust as important predictors of Facebook relationships. Cyberpsychology: Journal of Psychosocial Research on Cyberspace, 3(2).

Smith, H. J., Dinev, T., \& Xu, H. (2011). Information Privacy Research: An Interdisciplinary Review. MIS Quarterly, 35(4), 989-1015.

Spiliotopoulos, T., \& Oakley, I. (2013). Understanding Motivations for Facebook Use: Usage Metrics, Network Structure, and Privacy. In Proceedings of the 2013 ACM annual conference on Human Factors in Computing Systems - CHI '13 (pp. 3287-3296). ACM. https://doi.org/10.1145/2470654.2466449

Spiliotopoulos, T., \& Oakley, I. (2015). An exploratory study on the use of Twitter and Facebook in tandem. In Proceedings of the 2015 British HCI Conference on - British HCI '15 (pp. 299-300). New York, New York, USA: ACM Press. https://doi.org/10.1145/2783446.2783620

Statista. (2018). Device usage of Facebook users worldwide as of January 2018. Retrieved January 7, 2019, from https://www.statista.com/statistics/377808/distribution-of-facebookusers-by-device/

Steinfield, C., Ellison, N., \& Lampe, C. (2008). Social capital, self-esteem, and use of online social network sites: A longitudinal analysis. Journal of Applied Developmental Psychology, 29(6), 434-445. https://doi.org/10.1016/j.appdev.2008.07.002

Taddei, S., \& Contena, B. (2013). Privacy, trust and control: Which relationships with online 
self-disclosure? Computers in Human Behavior, 29(3), 821-826.

https://doi.org/10.1016/j.chb.2012.11.022

Taddicken, M. (2014). The 'Privacy Paradox' in the Social Web: The Impact of Privacy Concerns, Individual Characteristics, and the Perceived Social Relevance on Different Forms of Self-Disclosure. Journal of Computer-Mediated Communication, 19(2), 248-273. https://doi.org/10.1111/jcc4.12052

Tidwell, L. C., \& Walther, J. B. (2002). Computer-Mediated Communication Effects on Disclosure, Impressions, and Interpersonal Evaluations: Getting to Know One Another a Bit at a Time. Human Communication Research, 28(3), 317-348.

https://doi.org/10.1093/hcr/28.3.317

Tosun, L. P. (2012). Motives for Facebook use and expressing "true self" on the Internet. Computers in Human Behavior, 28(4), 1510-1517. https://doi.org/10.1016/j.chb.2012.03.018

Vitak, J. (2012). The Impact of Context Collapse and Privacy on Social Network Site Disclosures. Journal of Broadcasting \& Electronic Media, 56(4), 451-470. https://doi.org/10.1080/08838151.2012.732140

Wang, Y.-C., Burke, M., \& Kraut, R. (2016). Modeling Self-Disclosure in Social Networking Sites. In Proceedings of the 19th ACM Conference on Computer-Supported Cooperative Work \& Social Computing - CSCW '16 (Vol. 25, pp. 74-85). New York, New York, USA: ACM Press. https://doi.org/10.1145/2818048.2820010

Wang, Yanbo, Min, Q., \& Han, S. (2016). Understanding the effects of trust and risk on individual behavior toward social media platforms: A meta-analysis of the empirical evidence. Computers in Human Behavior, 56, 34-44. https://doi.org/10.1016/j.chb.2015.11.011

Wang, Yang, Leon, P. G., Acquisti, A., Cranor, L. F., Forget, A., \& Sadeh, N. (2014). A field trial of privacy nudges for facebook. In Proceedings of the 32nd annual ACM conference on Human factors in computing systems - CHI '14 (pp. 2367-2376). New York, New York, USA: ACM Press. https://doi.org/10.1145/2556288.2557413

Wanous, J. P., \& Hudy, M. J. (2001). Single-Item Reliability: A Replication and Extension. 
Organizational Research Methods, 4(4), 361-375.

https://doi.org/10.1177/109442810144003

Weiler, M. (2018). Measuring Real-World Tie Strength with Digital Footprint Data: An Assessment of Convergent Validity. In International Conference on Information Systems (ICIS). San Francisco, USA: Association for Information Systems.

Wellman, B., \& Wortley, S. (1990). Different Strokes from Different Folks: Community Ties and Social Support. American Journal of Sociology, 96(3), 558-588.

Wheeless, L. R., \& Grotz, J. (1976). Conceptualization and Measurement of Reported SelfDisclosure. Human Communication Research, 2(4), 338-346. https://doi.org/10.1111/j.1468-2958.1976.tb00494.x

Wheeless, L. R., \& Grotz, J. (1977). The measurement of trust and its relationship to selfdisclosure. Human Communication Research, 3(3), 250-257. https://doi.org/10.1111/j.1468-2958.1977.tb00523.x

Yang, C., \& Brown, B. B. (2015). Factors involved in associations between Facebook use and college adjustment: Social competence, perceived usefulness, and use patterns. Computers in Human Behavior, 46, 245-253. https://doi.org/10.1016/j.chb.2015.01.015

Yu, R. P. (2016). The relationship between passive and active non-political social media use and political expression on Facebook and Twitter. Computers in Human Behavior, 58, 413-420. https://doi.org/10.1016/j.chb.2016.01.019

Zhao, J., Wu, J., \& Feng, X. (2011). Information propagation in online social networks : a tiestrength perspective. Knowledge and Information Systems. https://doi.org/10.1007/s10115011-0445-x

Zimmer, J. C., Arsal, R. E., Al-Marzouq, M., \& Grover, V. (2010). Investigating online information disclosure: Effects of information relevance, trust and risk. Information and Management, 47(2), 115-123. https://doi.org/10.1016/j.im.2009.12.003 